\title{
IMPLEMENTATION OF PPTCT PROGRAM IN A RURAL TERTIARY REFERRAL CENTRE - A JOURNEY OF FIVE YEARS.
}

Gautam Mukhopadhyay, Sohini Bhattacharya, Shyamapada Pati, Shritanu Bhattacharya, Nandita Biswas, Samir Chandra Ghosh Roy

1. Associate Professor. Department of Obstetrics \& Gynaecology, North Bengal Medical College,

2. Associate Professor. Department of Obstetrics \& Gynaecology, North Bengal Medical College,

3. Professor. Department of Obstetrics \& Gynaecology, North Bengal Medical College,

4. Associate Professor. Department of Obstetrics \& Gynaecology, North Bengal Medical College,

5. RMO. Department of Obstetrics \& Gynaecology, North Bengal Medical College,

6. Professor. Department of Obstetrics \& Gynaecology, North Bengal Medical College,

\section{CORRESPONDING AUTHOR}

Gautam Mukhopadhyay

4A, Triveni Apartment.

Meghnad Saha Sarani. Pradhan Nagar,

Siliguri, Dist: Darjeeling. West Bengal- 734003

E-mail: gautam_in_66@yahoo.co.uk

Ph: 00919434377088

ABSTRACT: OBJECTIVE: to critically analyze the prevention of parent to child transmission (PPTCT) services offered by a teaching institute located in the Darjeeling district of West Bengal, since it started five years ago. METHOD: All the women registered in the antenatal clinic from $1^{\text {st }}$ January 2004 to $31^{\text {st }}$ December 2008 were tested for HIV after counseling. Spouse counseling and testing of spouse and children was done where possible. Antiretroviral prophylaxis with Nevirapine was given to laboring mothers and their neonates. All data were compiled retrospectively and analyzed. RESULTS: A total 26319 women were offered counseling during the period. The acceptance of testing rose from $66.32 \%$ in 2004 to $90.7 \%$ in 2008 . The highest seroprevalence was observed in 2007(0.84\%) which had dropped in 2008(0.44\%). The majority of the 112 seropositive women were rural residents, housewives, practicing no contraception, yet with some knowledge about HIV and its mode of transmission. There has been an increase in institutional delivery and cesarean section from 2004 to 2008. ARV prophylaxis with Nevirapine was given to all 35 women identified to be HIV positive before delivery. Out of 48 live born babies 46 received Nevirapine syrup. CONCLUSION: Seroprevalence has dropped with a greater awareness and acceptance of PPTCT program in the region.

KEY WORDS: PPTCT, HIV

INTRODUCTION: HIV infection poses one of the biggest threats to human health globally. Around 2.31 million people in India are living with the infection. ${ }^{1}$ Although it represents a drop from previous estimates, in absolute numbers; India's figure is still substantial. It is the third largest in the world and remains the largest in Asia.,3

Shortly after reporting the first AIDS case in 1986, the Government of India established a National AIDS Control Program. The transition of NACP from NACP I to NACP III has been a gradual, yet comprehensive consultative process. The National AIDS Control Organization (NACO) was established under the Ministry of Health and Family Welfare to implement this program. ${ }^{4}$ 
NACO envisions an India where every pregnant woman living with HIV has the choice to bring an HIV free baby into the world; has access to Integrated Counseling and Testing Centers (ICTCs), and those affected by HIV, treated with dignity and quality care.

The GOI has embarked on the ambitious goal of halting and reversing the HIV/AIDS epidemic by 2011, ahead of the 2015 target of the sixth Millennium Development Goal. ${ }^{6}$

2006 estimates indicate that although the overall prevalence of HIV has dropped, 26 districts have been identified with a rising figure. In West Bengal, prevalence has gone up from 0.21 to $0.31 \% .^{3}$ The HIV positivity among pregnant women is highest in the Darjeeling district $(1.04 \%) .^{7}$

The study aims to critically analyze the PPTCT services offered by our teaching institute located in the Darjeeling district of West Bengal since it started five years ago in first January 2004.The institute is the endorsed centre for ART treatment for AIDS/HIV in this region by NACO.

METHODOLOGY: The PPTCT started functioning from first January 2004 in our outdoor patients department of Obstetrics and Gynecology. It changed its name to ICTC in May 2008. It is staffed by two counselors and one laboratory technician, a faculty member as team leader supervising the work. All the women registered in our antenatal clinic from $1^{\text {st }}$ January 2004 to 31 included history taking, audiovisual display regarding transmission of HIV infection, flipcharts, condom demonstration and signing of consent form. The women who gave informed consent were tested for HIV. Spouse counseling was done where possible.

HIV testing procedure included three rapid tests - Coombs AIDS (Span diagnostics), Instacheck (Transasia Biomedical) and Quickcheck (Intec Product).

Specimen which tested positive with all three tests was considered positive according to national guideline. Post test counseling was done in a one to one basis. Spouse notification and counseling was done and previous children more than 18 months of age were tested for HIV.

Women who tested positive, after counseling decided whether to go for termination or continuation of pregnancy. Women choosing to continue pregnancy were advised to attend ANC regularly and LSCS was advised at term. Nevirapine, 200mg orally was given as prophylactic dose before surgery or when women arrived with labor pain. If delivery of baby did not occur within four hours, the dose was to be repeated. All neonates were given Nevirapine syrup 0.5 $\mathrm{ml} / \mathrm{kg}$ body weight within 72 hours of birth. The nursing staff in charge of labor room was provided with the names of the seropositive antenatal women so that antiretroviral (ARV) prophylaxis could be given even to those who concealed their HIV status at admission to labor room. In unbooked cases, HIV testing was done in labor room after proper counseling. LSCS was done when the mother was not in active labor. Counseling on infant feeding and contraception followed. All the data were compiled retrospectively and analyzed.

FINDINGS: A total number of 22674 antenatal cases attended the OPD from $1^{\text {st }}$ January 2004 to 31st December 2008. A higher number of 26319 women were offered counseling. Many antenatal women visiting private clinics opt for HIV testing at our center since the laboratories offering HIV testing are hardly reliable in this region. These women walk out with their reports without attending the room where antenatal check up and registration are done simultaneously. This accounts for this discrepancy. The percentage of women who accepted testing steadily rose from $66.32 \%$ in 2004 to $90.7 \%$ in 2008 . Acceptance of testing among spouse is better. It has 
remained steady at $100 \%$ in the last two years. The highest seroprevalence of HIV was observed in 2007 (0.84\%), which has dropped down to half in 2008(0.44\%). 12 discordant couples were recorded during this period out of 112 seropositive cases.

Table 2 shows the demographic characteristics of the seropositive women. The majority of the women were housewives in the age group 21-26 years, residing in rural areas, practicing no contraception, yet had some knowledge about HIV and its modes of transmission.

Table 3 lists the high risk behavior among seropositive women, among whom 23 disclosed to having multiple sexual partners. But since as high as 49 women did not reveal themselves, the table is not representative of the true picture prevalent among them.

Table 4 shows the therapeutic interventions undertaken in our institution to reduce mother to child transmission of HIV.

There has been an increase in institutional delivery as well as LSCS from 2004 to 2008. Only 5 out of 19 seropositive women attended the hospital for institutional delivery in 2004, of whom only one underwent LSCS. In 2008, out of the same number of seropositive women, six underwent LSCS of the 12 women who came for institutional delivery. This reflects the increase in awareness among the public.

48 live born babies during this period of five years. 33 were artificially fed .15 women chose to breastfeed their babies after counseling. ARV prophylaxis with Nevirapine was given to all 35 women who could be identified to be HIV positive before delivery. Three women who were on highly active anti retroviral therapy (HAART) with Zidovudine 300mg BD Lamivudine $150 \mathrm{mgBD}$ and Nevirapine $200 \mathrm{mg}$ BD and before pregnancy continued it till after delivery. Out of a total number of 48 live born babies; 46 received Nevirapine syrup.

DISCUSSION: The West Bengal State AIDS Prevention and Control Society introduced PPTCT services in our teaching institution, which is also the tertiary referral centre for northern districts including Darjeeling on $1^{\text {st }}$ January 2004.

Out of a total 26319 woman who attended counseling session, there has been a steep rise in the acceptance of HIV testing from $66.32 \%$ in 2004 to $90.7 \%$ in 2008 . The similar rise in spouse's acceptance of test is truly appreciable as it has stood at $100 \%$ for the last two years. The acceptance of test has been reported to be in the range of $36 \%$ to $99 \%$ among antenatal women while spouse acceptance has been reported to be poor.8,9,10 as most husbands do not accompany their wives to antenatal visits, we missed the opportunity of counseling them. But the acceptance of HIV testing is higher among them than the women probably because of their access to print, or audiovisual media because of their outdoor life and comparatively better literacy.

The seroprevalence of HIV among the antenatal women ranged from $0.37 \%$ to $0.84 \%$. Different studies across the PPTCT centers in West Bengal recorded a seroprevalence of $0.1 \%$ to $0.4 \%$ in 2004.9,11,12 There has been a rising trend since then. In 2008, Darjeeling district in which our center is located, recorded a rise to $1.04 \%$, the highest in the state. ${ }^{7}$ our figures were lower as our center caters to other districts of north Bengal as well, where seroprevalence was lower. The downward trend in seroprevalence from $0.84 \%$ in 2004 to 0.445 in 2008 was encouraging, yet is higher than the state's average of $0.3 \%{ }^{3}$

The demographic profile of seropositive women reveals that majority were housewives from rural areas in the age group 21-26 years, who were not using any contraception. Similar were the observations by other authors.,9,12 Although results from the 2005 BBC World Service Trust KAP survey showed $82 \%$ awareness about HIV/AIDS in rural population, ${ }^{4}$ our study 
showed a low state of awareness at $22.3 \%$ among HIV positive women who were mostly rural residents. This call for an urgent effort on behalf of both medical and non medical personnel to provide proper information about HIV/AIDS to the rural population in this area in a manner that is comprehensible and acceptable to them taking into account the low level of literacy. Most of the information in form of posters or leaflets -are not being helpful here. The high incidence of STD indicates that sexual promiscuity is higher than disclosed in the study. This conforms well with previous authors. ${ }^{9,12}$

A total number of 17 mothers underwent LSCS during this period. Though the average rate is $34 \%$, there has been an increase from $20 \%$ in 2004 to $50 \%$ in 2008 . This is higher than reported in previous studies. ${ }^{11,12}$ Hence there is both an increase in consciousness among both the health care givers as well as the mothers regarding the importance of this procedure to be undertaken before rupture of membranes to reduce the mother to child transmission of HIV. It is sad that only 49 of the 112 seropositive women who continued with pregnancy chose to undergo institutional delivery, among whom 35 received Nevirapine prophylaxis. The 14 women could not be given Nevirapine as they hid their HIV status during admission. Since the counselors and technicians work from 9.AM to 4 PM six days a week, these women who got admitted with labor pain in the night and delivered before morning or on Sundays could not be tested by them. Hence many unbooked cases are still not being tested.

Among the ten women who opted for MTP, two wanted to rear a child badly and were eager to comply with our advices. The fear of apathy and discrimination by the paramedical staff in the hospital prompted them to terminate their pregnancy. NACO still has a long way to go to implement an environment where human rights are respected and infected members live a life without stigma or discrimination.

Two neonates delivered at our hospital did not receive ART prophylaxis as Nevirapine syrup was not available at the PPTCT center for a month in the initial phases when the program was not so well organized. The women who chose to deliver at home or in private hospitals could not be traced.

We met 12 discordant couples where the male partner was HIV negative. All were diagnosed in pregnancy, were advised to use condom. Although no seroconversion was recorded, it is reported that as high as $32 \%$ of pregnancies and HIV transmissions occur with regular use of condom in serodiscordant couples. ${ }^{13}$ Rather HAART should be given to the infected partner to suppress viremia that would minimize both the risk of transmission as well as infection of the partner.

The scenario shall improve only if the following measures are taken -

1) A greater vigilance to counsel the mothers to uphold their confidence regarding the need, safety and efficacy of delivery in their particular institution so that they may get the benefit of PPTCT program to minimize vertical transmission.

2) A greater awareness by constant persuasion among paramedical staff dealing with HIV mothers in the hospital, so that they are treated with dignity and care.

3) Intersectoral coordination between government and private hospitals so that the women who come for delivery in private hospitals may be identified and made to receive ART prophylaxis and followed up.

4) Recruitment of more counselors and technicians so that testing may be done 24 hours a day all week 
5) A system to be devised by which the women and children testing HIV positive may be followed up after discharge. Mobile phones may be useful as many nowadays possess them.

CONCLUSION: Although the new methodology indicates an overall lower incidence of HIV infection than before, it does not mean a decline in the epidemic. It only shows that the epidemic is under control because of enormous effort and mobilization over the past decade. There is no place for complacence since in absolute numbers; India's HIV figure is still substantial.

ACKOWLEDGEMENT: We thank the Medical Superintendent and Vice Principal of our hospital and West Bengal State AIDS Prevention and Control Society for utilizing hospital data for the study.

\section{REFERENCES:}

1. India HIV and AIDS statistics. HIV \& AIDS information from AVERT.org. http://www.avert.org/indiaaids.htm (accessed on 10.07.2009.)

2. The Big picture. HIV data. National AIDS Control Organization. Ministry of Health and Family Welfare. Government of India.http://www.nacoonline.org/Quick_Links/HIV_Data/ (accessed on 10.07.2009)

3. Breaking down the numbers. HIV data. National AIDS Control Organization. Ministry of Health and Family Welfare. Government of India.http://www.nacoonline.org/Quick_Links/HIV_Data/ (accessed on 10.07.2009)

4. HIV/AIDS South Asia -India . State of the epidemic/ Risk factors/ National response to HIV/AIDS/ Issues and Challenges: Priority areas/ World Bank response. http://web.worldbank.org/WBSITE/EXTERNAL/COUNTRIES/SOUTHASIAEXT/EXTSAR EGTOPHEANUT/EXTSAREGTOPHIVAIDS/0,,contentMDK:20288516 menuPK:568874 pagePK:34004173 piPK:34003707 theSitePK:496967,00.html (accessed on 10.07.2009)

5. Visions and values. National AIDS Control Organization. Ministry of Health and Family Welfare. Government of India http://www.nacoonline.org/About_NACO/Vision_and_Values/ (accessed on 10.07.2009)

6. 6.3 $3^{\text {rd }}$ National HIV/AIDS Control Project (NACP III). http://www.worldbank.org.in/WBSITE/EXTERNAL/COUNTRIES/SOUTHASIAEXT/INDI AEXTN/0,,contentMDK:21397693 pagePK:141137 piPK:141127 theSitePK:295584,0 0.html (accessed on 10.07.2009)

7. Quarterly CMIS Bulletin April-Sept.,08. National AIDS Control Organization (Department of AIDS Control) Ministry of Health and Family Welfare. Government of Indiahttp://www.nacoonline.org/upload/Publication/M\&E\%20Surveillance,\%20Resea rch/Quarterly\%20CMIS\%20Bulletin\%20April-Sept\%2008\%20Bookmark.pdf (accessed on 10.07.2009).

8. Maitra N, Kavishkar AB, Dinkar A, Desai VA. Antenatal HIV Testing. J Obstet Gynecol India.:Jan/Feb 2006.Vol.56, No1,56-58.

9. Goswami S, Chakravarty PS. Epidemiology of HIV in antenatal women in an urban set up. J Obstet Gynecol India Mar/Apr 2008.Vol.58,No 2 134-137. 
10. Jeve Yadava B ,Mishra V.Response to antenatal HIV testing and prevention of parent to child transmission:an experience in a peripheral hospital in India. J Obstet Gynecol India. Mar/Apr 2009.Vol 59,No2.124-126.

11. Bal R, Talukdar A, Roy K. Prevention of parent o child transmission of HIV- scenario of West Bengal. J Obstet Gynecol India.May/June 2008.Vol.58,No.3:221-225.

12. Chaudhuri S, bose S, Talukdar A, Ghosh US. Seroprevalence and utilization of therapeutic intervention in PPTCT services in a teaching hospital in Kolkata. . J Obstet Gynecol India May/Jun 2007.Vol 57.No 3:251-256.

13. Allen S, Meinzen-Derr J, Kautzman M, Zulu I, Trask S, Fideli U,Musonda R,Kasolo F, Gao F, Haworth A.Sexual behaviour of HIV discordant couples after HIV counseling and testing.AIDS. Mar 2003 28;17(5):733-40.

14. Barreiro P, Castilla JA, Labarga P, Soriano V.Is natural conception a valid option for HIVserodiscordant couples?Hum Reprod Sep.2007 22(9):2353-8.Epub 2007 Jul 19. 
Table 1: Uptake of PPTCT services in our centre

\begin{tabular}{|c|c|c|c|c|c|c|}
\hline & 2004 & 2005 & 2006 & 2007 & 2008 & Total No \\
\hline Antenatal new cases attending OPD: & 6065 & 4045 & 4214 & 4215 & 4135 & 22674 \\
\hline No. of women counseled: & 5654 & 5748 & 5293 & 4932 & 4692 & 26319 \\
\hline No. of spouse counseled: & 1668 & 2301 & 2594 & 2815 & 3100 & 12478 \\
\hline No. of unbooked cases counseled: & 123 & 296 & 285 & 347 & 359 & 1410 \\
\hline No. of women accepting Test & 3760 & 3924 & 4230 & 4250 & 4258 & 20422 \\
\hline
\end{tabular}

Percentage of women accepting Test $66.32 \% 68.26 \%$ 79.91\% 86.17\% 90.75\% 78.28\%

$\begin{array}{lllllll}\text { No. of spouse accepting Test } \quad 1219 & 2000 \quad 2531 & 2815 & 3100 & 11665\end{array}$

Percentage of spouse accepting Test $73.08 \% \quad 86.91 \% \quad 97.57 \% \quad 100 \% \quad 100 \% \quad 91.51 \%$

$\begin{array}{llllll}\text { No. of children accepting Test } 7 & 9 & 11 & 11 & 10 & 48\end{array}$

$\begin{array}{lllllll}\text { No. of HIV+ve women } & 19 & 22 & 16 & 36 & 19 & 112\end{array}$

$\begin{array}{lllllll}\text { No. of HIV+ve spouse } & 12 & 21 & 23 & 32 & 16 & 104\end{array}$

No. of previous children of

$\begin{array}{lllllll}\text { HIV +ve women who tested } & 4 & 1 & 2 & 2 & 2 & 11\end{array}$

HIV +ve

$\begin{array}{lllllll}\text { No. of HIV -ve spouse } & 2 & 1 & 2 & 4 & 3 & 12\end{array}$

(Discordant couple)

HIV seropositivity in

Antenatal women tested

$\begin{array}{llllll}0.50 \% & 0.56 \% & 0.37 \% & 0.84 \% & 0.44 \% & 0.54 \%\end{array}$

HIV seropositivity in

Spouse tested

$0.98 \% \quad 0.85 \% \quad 0.90 \% \quad 1.13 \% \quad 0.51 \% \quad 0.87 \%$

HIV seropositivity in

Children of HIV+ve women $\quad 57.15 \% \quad 11.1 \% \quad 18.18 \% \quad 18.18 \% \quad 20 \% \quad 24.92 \%$ 
Table 2: Demographic profile of HIV+ve women;

Age

15-20 years

21-26 years

27-32 Years

33-38 years

39-44 Years

$>45$ Years

Residence

Rural

Urban

Occupation

Housewife

Hotel Cook

Student

Commercial Sex worker

Home servant

Govt. Servant

Daily Wage Laborer

Others

\section{Addiction:}

Alcohol

Smoking

Tobacco Chewing

Nothing

Not disclosed

Contraceptive Use

None

Barrier

OCP

IUCD

Knowledge about HIV

Very little

Good

None
Total No (\%)

$31(27.6 \%)$
$58(51.7 \%)$
$19(16.9 \%)$
$04(3.8 \%)$
00
00

$94(83.9 \%)$

$18(16.1 \%)$

96(85.7\%)

$01(0.9 \%)$

$01(0.9 \%)$

$03(2.6 \%)$

$01(0.9 \%)$

$01(0.9 \%)$

$04(3.5 \%)$

05(4.4\%)

$03(2.7 \%)$

06(5.3\%)

$12(10.7 \%)$

47(41.9\%)

$44(39.2 \%)$

$83(74.1 \%)$

$02(1.9 \%)$

$23(20.5 \%)$

$04(3.5 \%)$

$71(63.3 \%)$

$25(22.3 \%)$

$16(14.4 \%)$ 
Table 3: High Risk Behavior among HIV +ve women

High Risk Behavior

Multiple Sexual Partners

Associated STD's

I.V drug User

Recipient of Blood / Blood products

Not Known

\section{Number}

$23(20.5 \%)$

$31(27.6 \%)$

00

09(8\%)

$49(43.7 \%)$

Table 4: Therapeutic Interventions done to prevent mother to child transmission of HIV

$\begin{array}{lllllll}\text { Interventions } & 2004 & 2005 & 2006 & 2007 & 2008 & \text { Total No }\end{array}$

Institutional

Delivery

5

$$
7
$$

8

$17 \quad 12 \quad 49$

Vaginal delivery

4

6

5

$11 \quad 6 \quad 32$

Cesarean section

1

1

3

$\begin{array}{lll}6 & 6 & 17\end{array}$

MTP

1

1

0

$\begin{array}{lll}7 & 1 & 10\end{array}$

Live Birth

$$
5
$$

6

8

17

$12 \quad 48$

Breastfeeding

1

5

3

4

$2 \quad 15$

Artificial feeding

4

1

5

13

10

33

Antiretroviral

Prophylaxis to mother 4

3

8

8

$12 \quad 35$

Antiretroviral

Prophylaxis to

Neonate

3

6

$\begin{array}{ll}8 & 17\end{array}$

$12 \quad 46$

Tubal ligation

1

1

$0 \quad 2$

26 